\section{BRAZIULIAN JOURNAL}

OF MEDICAL AND BIOLOGICAL RESHARCH

www.bjournal.com.br
ISSN 0100-879X

Volume 43 (9) 812-913 September 2010

BIOMEDICAL SCIENCES

AND

CLINICAL INVESTIGATION

Braz J Med Biol Res, September 2010, Volume 43(9) 837-842

doi: 10.1590/S0100-879X2010007500088

Characterization of angiotensin-converting enzymes 1 and 2 in the soleus and plantaris muscles of rats

T. Fernandes, N.Y. Hashimoto and E.M. Oliveira

The Brazilian Journal of Medical and Biological Research is partially financed by

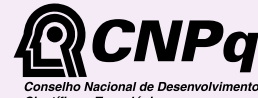

Ministério cientifico e Tecnológico

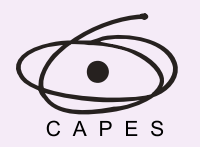

Ministério da Educação

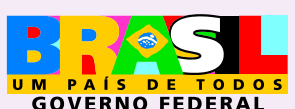

GOVERNO FEDERAL
DFAPESP

Institutional S ponsors
Ф SHIMADZU
Hotsite of proteomics metabolomics developped by: 


\title{
Characterization of angiotensin-converting enzymes 1 and 2 in the soleus and plantaris muscles of rats
}

\author{
T. Fernandes, N.Y. Hashimoto and E.M. Oliveira
}

Laboratório de Bioquímica da Atividade Motora, Departamento de Biodinâmica do Movimento do Corpo Humano, Escola de Educação Física e Esporte, Universidade de São Paulo, São Paulo, SP, Brasil

\begin{abstract}
Angiotensin-converting enzymes 1 (ACE1) and 2 (ACE2) are key enzymes of the renin-angiotensin system, which act antagonistically to regulate the levels of angiotensin II (Ang II) and Ang-(1-7). Considerable data show that ACE1 acts on normal skeletal muscle functions and architecture. However, little is known about ACE1 levels in muscles with different fiber compositions. Furthermore, ACE2 levels in skeletal muscle are not known. Therefore, the purpose of this study was to characterize protein expression and ACE1 and ACE2 activities in the soleus and plantaris muscles. Eight-week-old female Wistar rats $(\mathrm{N}=8)$ were killed by decapitation and the muscle tissues harvested for biochemical and molecular analyses. ACE1 and ACE2 activities were investigated by a fluorometric method using Abz-FRK(Dnp)P-OH and Mca-YVADAPK(Dnp)-OH fluorogenic substrates, respectively. ACE1 and ACE2 protein expression was analyzed by Western blot. ACE2 was expressed in the skeletal muscle of rats. There was no difference between the soleus (type I) and plantaris (type II) muscles in terms of ACE2 activity (17.35 \pm 1.7 vs $15.09 \pm 0.8 \mathrm{uF} \cdot \mathrm{min}^{-1} \cdot \mathrm{mg}^{-1}$, respectively) and protein expression. ACE1 activity was higher in the plantaris muscle than in the soleus (71.5 $\pm 3.9 \mathrm{vs} 57.9 \pm 1.1 \mathrm{uF} \cdot \mathrm{min}^{-1} \cdot \mathrm{mg}^{-1}$, respectively). Moreover, a comparative dose-response curve of protein expression was established in the soleus and plantaris muscles, which indicated higher ACE1 levels in the plantaris muscle. The present findings showed similar ACE2 levels in the soleus and plantaris muscles that might result in a similar Ang II response; however, lower ACE1 levels could attenuate Ang II production and reduce bradykinin degradation in the soleus muscle compared to the plantaris. These effects should enhance the aerobic capacity necessary for oxidative muscle activity.
\end{abstract}

Key words: Renin-angiotensin system; ACE1; ACE2; Rat skeletal muscle

\section{Introduction}

The renin-angiotensin system (RAS) has been identified as an important target in the regulation of blood pressure as well as fluid and electrolyte balance $(1,2)$. Angiotensinconverting enzyme (ACE1) converts angiotensin I to angiotensin II (Ang II) and inactivates bradykinin, a vasodilator peptide, thereby potentiating the vasopressor response mediated by Ang II $(1,2)$.

Recent data have demonstrated that the skeletal muscle RAS reflects a combination of in situ synthesis of RAS components and uptake of these constituents from the circulation (3); however, the activity of ACE1 in the human skeletal muscle does not correlate with that of serum ACE1 (4). Skeletal muscle ACE1 activity has been demonstrated in cell membrane fractions and cultured myoblasts (5). In addition, RAS components are present throughout the skeletal muscle microcirculation, including endothelial cells, vascular smooth muscle cells, and other vessel-associated cells (6).

Several studies have shown that ACE1 inhibition promotes morphological and functional alterations such as an increased proportion of type I fibers and angiogenesis $(7,8)$. Indeed, ACE insertion/deletion polymorphism is clear evidence that different ACE1 levels may induce prevalence of type I or II fibers associated with skeletal muscle phenotype and performance $(9,10)$.

Half a century after the discovery of ACE1, a new homolog of the enzyme, termed ACE2, was identified (11). The substrates identified for ACE2 include Ang I and Ang II, which are cleaved to a nonapeptide Ang-(1-9) and a heptapeptide Ang-(1-7), respectively. The conversion of

Correspondence: E.M. Oliveira, Departamento de Biodinâmica do Movimento do Corpo Humano, Escola de Educação Física e Esporte, USP, Av. Professor Mello Moraes, 65, 05508-900 São Paulo, SP, Brasil. Fax: +55-11-3813-5921. E-mail: edilamar@usp.br

Received January 23, 2010. Accepted July 22, 2010. Available online August 27, 2010. Published September $13,2010$. 
Ang II to Ang-(1-7) is the preferred pathway, with a 500fold greater efficiency compared with the Ang I cleavage pathway (11-13).

ACE2 has been implicated in Ang-(1-7) formation, with a key role in vasodilation and antiproliferactive effects. ACE2 has also been described as an enzyme that works as a negative regulator of the RAS, counterbalancing the multiple functions of ACE1 (12,13). Together, ACE1 and ACE2 counterbalance the Ang II and Ang-(1-7) concentration, permitting a balance between the pressor-trophic effects of Ang II and the opposing depressor-antitrophic effects of Ang-(1-7).

ACE2 is expressed predominantly in the heart, kidneys, and testes, and at a lower level in a wide variety of tissues (11-13); however, there have been no publications on the ACE2 in skeletal muscle.

The objective of the present study was to characterize the protein expression and activities of ACE1 and ACE2 in skeletal muscles with different fiber compositions. The soleus and plantaris muscles were chosen because they are well known to have a distribution of fibers with different contractile and metabolic characteristics. We tested two hypotheses: 1) that ACE2 is expressed in skeletal muscle and 2) that plantaris muscle (predominance of type II fibers) can display higher ACE1 levels compared to soleus muscle (predominance of type I fibers) contributing to the glycolytic phenotype. Therefore, new information on the skeletal muscle RAS and new insights into the actions of ACE2 will be provided here.

\section{Material and Methods}

Female Wistar rats (180-220 g, N=8) were used in the present investigation and handled according to approved Institutional guidelines. Rats were maintained on a 12:12$\mathrm{h}$ dark-light cycle in a temperature-controlled environment $\left(22^{\circ} \mathrm{C}\right)$, with free access to standard laboratory chow (Nuvital Nutrientes S/A, Brazil) and tap water. The study was carried out according to the Ethical Principles in animal research adopted by the Brazilian College of Animal Experimentation (www.cobea.org.br) and was approved by the Ethics Committee of the University of São Paulo (protocol \#2006/04). Rats were killed by decapitation and soleus, plantaris, heart, and lungs were harvested for biochemical and molecular analyses.

The activity of skeletal muscle ACE1 was determined by a fluorometric assay (14) of samples from the soleus and plantaris tissues obtained from Wistar rats, frozen in liquid nitrogen, and stored at $-80^{\circ} \mathrm{C}$. Briefly, the homogenate supernatant was incubated for $60 \mathrm{~min}$ at $37^{\circ} \mathrm{C}$ with a fluorogenic substrate containing $10 \mu \mathrm{M}$ Abz-FRK(Dnp) $\mathrm{P}-\mathrm{OH}$ (Abz = o-aminobenzoic acid; Dnp = dinitrophenyl) in $0.1 \mathrm{M}$ Tris- $\mathrm{HCl}$ buffer, $50 \mathrm{mM} \mathrm{NaCl}$, and $10 \mathrm{mM} \mathrm{ZnCl}_{2}, \mathrm{pH}$ 7.0. The hydrolysis rate of the intramolecularly quenched fluorogenic substrate Abz-FRK(Dnp)P-OH was assessed with fluorometer $\lambda_{\mathrm{ex}}=320 \mathrm{~nm}$ and $\lambda_{\mathrm{em}}=420 \mathrm{~nm}$. Measurements were performed in triplicate, and ACE1 activity values are reported as $\mathrm{UF} \cdot \mathrm{min}^{-1} \cdot \mathrm{mg}^{-1}$. The specificity of the assay was demonstrated by complete inhibition of hydrolysis by 0.5 $\mu \mathrm{M}$ captopril (Sigma-Aldrich, USA). Protein was determined by the method of Bradford using bovine serum albumin as standard (Bio-Rad Protein Assay, USA).

The activity of ACE2 was also determined in skeletal muscle tissue by a method similar to the one described above. The fluorogenic peptide substrate McaYVADAPK(Dnp)-OH (R\&D Systems, USA) in $0.2 \mathrm{M}$ Tris- $\mathrm{HCl}$ buffer, $200 \mathrm{mM} \mathrm{NaCl}, \mathrm{pH}$ 7.5, which is hydrolyzed with high affinity by ACE2, was employed. Captopril, a specific ACE1 inhibitor, was used as negative control for the assays because it does not inhibit ACE2 activity. The specificity of the assay was demonstrated by inhibition of hydrolysis by 0.1 MM DX600 (Phoenix Pharmaceuticals, USA), a specific ACE2 inhibitor.

Soleus and plantaris protein expression was demonstrated by Western blot. Briefly, liquid nitrogen frozen tissues were homogenized in a buffer containing $0.1 \mathrm{M}$ Tris- $\mathrm{HCl}$, $50 \mathrm{mM} \mathrm{NaCl}, 1 \mathrm{mM}$ 4-chloromercuribenzoic acid, $9.1 \mathrm{mM}$ o-phenanthroline, $1 \mathrm{mM}$ PMSF, and $0.12 \mathrm{mM}$ pepstatin $\mathrm{A}$, to prevent the in vitro production and degradation of angiotensin peptides and a protease inhibitor cocktail (1:100, catalog No. P2714, Sigma-Aldrich).

Samples were loaded and subjected to SDS-PAGE on $7.5 \%$ polyacrylamide gels. After electrophoresis, proteins were electro-transferred to a nitrocellulose membrane (Amersham Biosciences, USA). The dose-response curve for protein $(30,50,80$, and $100 \mu \mathrm{g})$ was used, and transfer efficiency was monitored by $0.5 \%$ Ponceau S staining of the blotted membrane. The latter was then incubated in a blocking buffer ( $5 \%$ nonfat dry milk, $10 \mathrm{mM}$ Tris- $\mathrm{HCl}, \mathrm{pH}$ 7.6, $150 \mathrm{mM} \mathrm{NaCl}$, and $0.1 \%$ Tween 20) for $2 \mathrm{~h}$ at room temperature, and then incubated overnight at $4{ }^{\circ} \mathrm{C}$ with a mouse anti-ACE (clone 2E2) monoclonal antibody (1:1000; Chemicon International, USA) and an anti-ACE2 (T-17) polyclonal antibody (1:1000; Santa Cruz Biotechnology Inc., USA). Binding of the primary antibody was detected with the use of peroxidase-conjugated secondary antimouse antibodies for ACE1 and of anti-goat antibodies for ACE2 (1:3000; Zymed Laboratories, USA), for $1 \mathrm{~h}$ and 30 min at room temperature, and developed using enhanced chemiluminescence (Amersham Biosciences) detected by autoradiography. Quantification analysis of the blots was performed with the Scion Image software (based on $\mathrm{NIH}$ Image, USA). Skeletal muscle $\alpha$-tubulin expression levels were used to control the quantity of protein carried.

\section{Results}

Figure 1 shows the characterization of ACE1 in two kinds of skeletal muscle, the soleus and the plantaris. ACE1 activities were $57.9 \pm 1.1$ and $71.5 \pm 3.9 \mathrm{uF} \cdot \mathrm{min}^{-1} \cdot \mathrm{mg}^{-1}$, 
respectively. However, the lung ACE1 activity was approximately 10 -fold higher $(564.7 \pm 2.9$ $\mathrm{uF} \cdot \mathrm{min}^{-1} \cdot \mathrm{mg}^{-1}$ ) than those detected in both skeletal muscles (Figure 1A). Moreover, a comparative dose-response curve for ACE1 protein expression was confirmed by protein load. Figure 1B depicts representative blots of ACE1 in the soleus and plantaris muscles as well as in $\alpha$-tubulin. In agreement, Figure $1 \mathrm{C}$ corresponds to the quantitative analysis of the dose-response curve for plantaris ACE1 protein expression, which provided 8857 arbitrary units (a.u.) for $30 \mu$ g protein, 15,643 a.u. for $50 \mu \mathrm{g}, 21,695$ a.u. for $80 \mu \mathrm{g}$, and 27,177 a.u. for $100 \mu \mathrm{g}$. In the soleus, the dose-response curve for ACE1 protein expression gave 5756 a.u. for $30 \mu \mathrm{g}$ protein, 7921 a.u. for $50 \mu g, 12,386$ a.u. for $80 \mu g$, and $19,691 \mathrm{a} . \mathrm{u}$. for $100 \mu \mathrm{g}$. The rat lung $(20,467$ a.u. for $30 \mu \mathrm{g}$ protein) was used as positive control of ACE1 protein expression.

Figure 2 describes the characterization of ACE2 in skeletal muscle. The ACE2 activities in the soleus and plantaris muscles were $17.35 \pm$ 1.7 and $15.09 \pm 0.8 \mathrm{uF} \cdot \mathrm{min}^{-1} \cdot \mathrm{mg}^{-1}$, respectively; however, the heart displayed higher ACE2 activity $\left(24.98 \pm 1.7 \mathrm{uF} \cdot \mathrm{min}^{-1} \cdot \mathrm{mg}^{-1}\right)$ than both skeletal muscles (Figure 2A). Captopril did not blockACE2 activity, showing that the substrate is specific for ACE2. The ACE2 activity was blocked by DX600. Figure 2B depicts representative blots of ACE2 in the soleus and plantaris muscles as well as in a-tubulin. In agreement, Figure 2C displays the quantitative analysis of the dose-response curve for plantaris ACE2 protein expression, namely 4859 a.u. for $30 \mu \mathrm{g}$ protein, 9059 a.u. for $50 \mu \mathrm{g}$, 11,539 a.u. for $80 \mu \mathrm{g}$, and 15,846 a.u. for $100 \mu \mathrm{g}$. In the soleus, the dose-response curve for soleus ACE2 protein expression yielded similar values, more specifically 4082 a.u. for $30 \mu$ g protein, 6770 a.u. for $50 \mu \mathrm{g}, 11,193 \mathrm{a.u}$. for $80 \mu \mathrm{g}$, and 15,374 a.u. for $100 \mu \mathrm{g}$. The rat heart (10,010 a.u. for $30 \mu \mathrm{g}$ protein) was the positive control for ACE2 protein expression and exhibited 2-fold higher expression of ACE2 compared to skeletal muscle.

\section{Discussion}

The present study identified the activity and protein expression of ACE1 and ACE2 in skeletal muscles with a predominance of different types of fiber. The results demonstrated that 1) ACE2 is expressed in the skeletal muscle of rats, 2) there is no difference between the soleus (type I fibers) and the plantaris (type II fibers) in terms of ACE2 activity and protein expression, and 3) the plantaris displayed higher ACE1 activity and
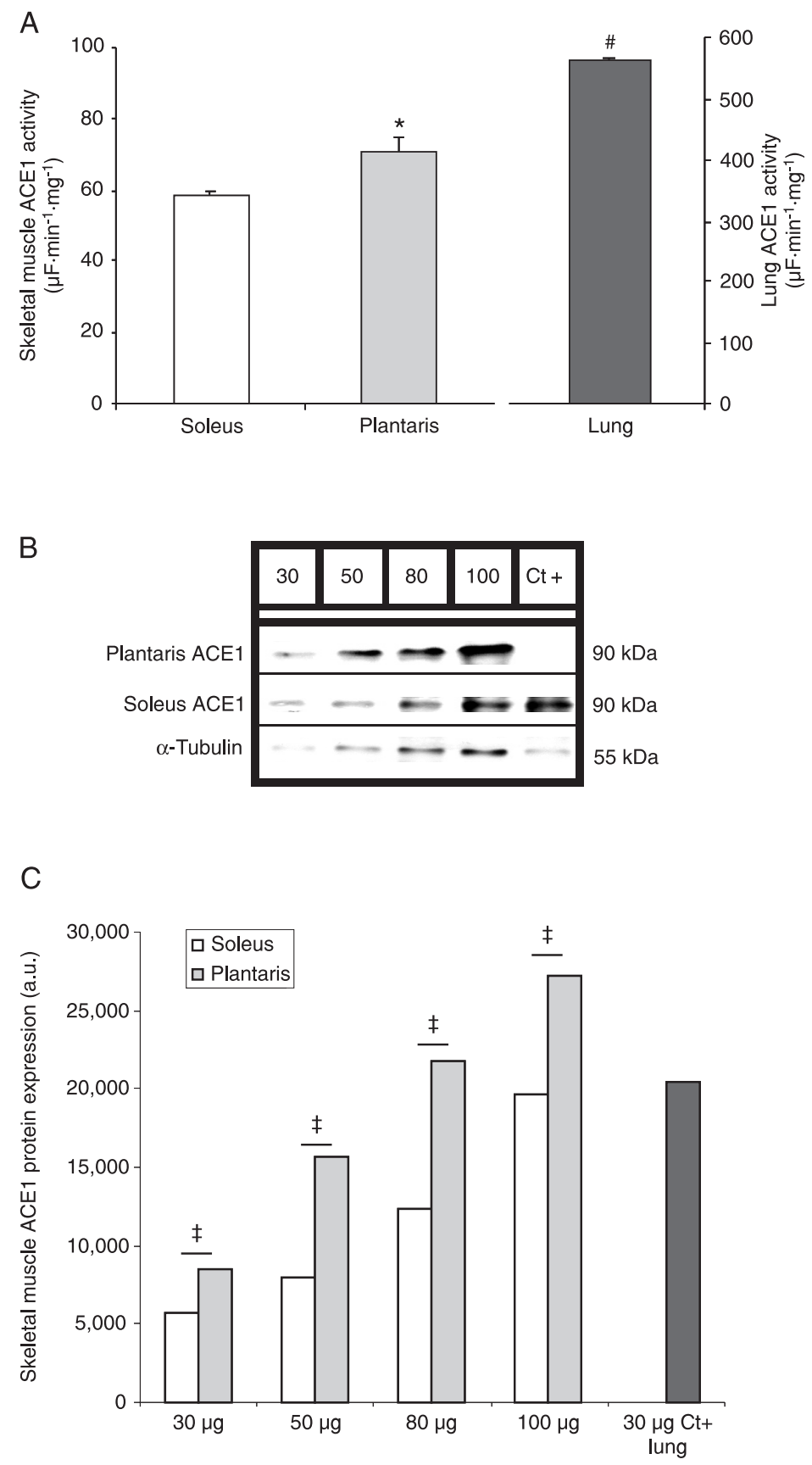

Figure 1. ACE1 in the skeletal muscle. $A$, Skeletal muscle ACE1 activity reported as means \pm SEM for 8 rats in each group. $B$, Representative blots of plantaris ACE1, soleus ACE1, and a-tubulin. $C$, Representative figure of soleus and plantaris ACE1 protein expression in Wistar rats. Note that the plantaris muscle displayed higher activity than the soleus and that both muscles presented a dose-response curve for ACE1 protein expression due to an increase in protein $(30,50,80$, and $100 \mu \mathrm{g}$ protein). Also, the plantaris muscle presented increased ACE1 protein expression compared to the soleus muscle. The rat lung was used as positive control $(\mathrm{Ct}+)$ for ACE1 activity and protein expression. $\mathrm{ACE}=$ angiotensin-converting enzyme. ${ }^{*} \mathrm{P}<0.05$ compared to soleus muscle; ${ }^{\mathrm{P}}<0.0001$ compared to soleus and plantaris muscles; $¥ \mathrm{P}<0.01$ compared to soleus muscle (Student $t$-test). 
protein levels than the soleus muscle.

Fast (type II) and slow (type I) twitch muscle fibers exhibit different characteristics with respect to functional properties due to differences in the isoforms and in the level of expression of most muscle proteins. The predominance of oxidative metabolism in the soleus muscle, where type I fibers predominate and there is a larger amount of capillaries as well as higher oxygen support, is important for the maintenance of the aerobic capacity of this muscle. The lower ACE1 levels in the soleus muscle compared with the plantaris muscle might contribute to decreased bradykinin degradation, thereby potentiating bradykinin concentration, a potent activator of the L-arginine-nitric oxide pathway. This may promote vasodilation and angiogenesis. Indeed, low ACE1 levels have previously been shown to cause nitric oxide accumulation, thus inducing vasodilation and angiogenesis by bradykinin receptors $(3,8)$. In agreement, kinins inhibit growth processes, consequently leading to high levels of ACE1 in the plantaris muscle. The latter is well known for containing a larger proportion of type II fibers and is responsible for producing greater force per unit of cross-sectional area, thereby affecting muscle strength through elevated Ang II levels (10). Previous data regarding the role of Ang II in the control of skeletal muscle mass are controversial. Ang II has been shown to promote muscle atrophy (15); nevertheless, other studies have reported that Ang II induces skeletal muscle hypertrophy associated with strength gain $(16,17)$.

The results show that the lower ACE1 activity and levels in the soleus muscle compared to the plantaris could attenuate Ang II production and reduce bradykinin degradation, which favors vasodilation, the formation of new vessels, and oxygen and substrate delivery. Taken together, these effects should enhance the aerobic capacity necessary for oxidative muscle activity.

In patients with heart failure, chronic therapy with ACE1 inhibitors improves endothelial function and increases the proportion of slow twitch fibers, the oxidative capacity, and the capillary density, thereby enhancing aerobic capacity and skeletal muscle perfusion $(3,7)$.

ACE insertion/deletion polymorphism may be a possible genetic factor associated with excellence in sports $(9,10)$. Human studies have identified an increased frequency of the I allele in elite endurance athletes, long-distance runners, rowers, and mountaineers, as well as an increased occurrence of the $D$ allele with strength gains in power performance $(3,9,10)$. An excess

B

C of the I allele is associated with decreased ACE1 activity and prevalence of type I fibers, revealing a relationship between this sort of polymorphism and human performance in endurance sports $(3,9)$. In contrast, the D allele is asso-
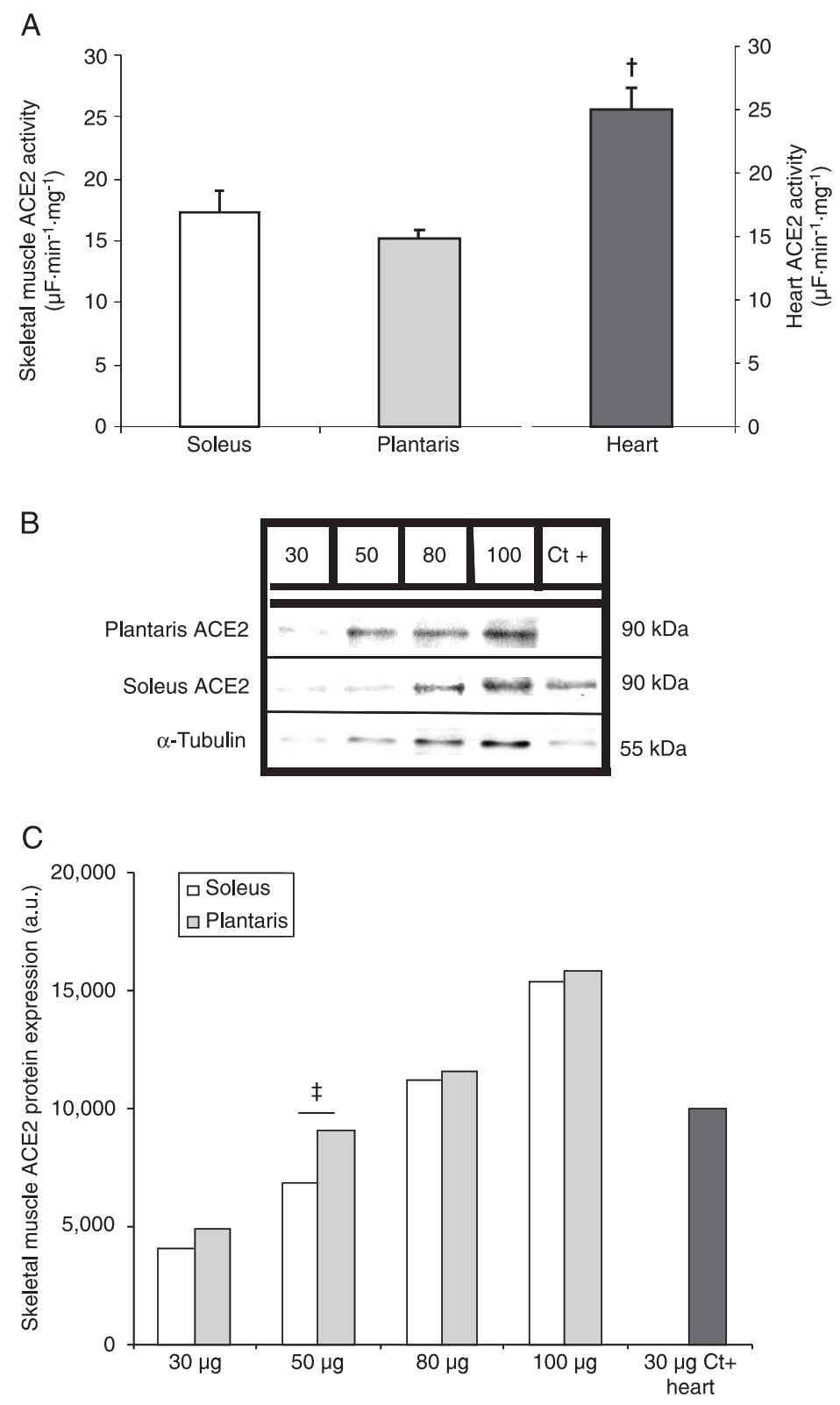

Figure 2. ACE2 in the skeletal muscle. $A$, Skeletal muscle ACE2 activity reported as means \pm SEM for 8 rats in each group. $B$, Representative blots of plantaris ACE2, soleus ACE2, and a-tubulin. C, Representative figure of soleus and plantaris ACE2 protein expression in Wistar rats. Note that the soleus and plantaris muscles displayed similar ACE2 activity and that both muscles presented a dose-response curve for ACE2 protein expression due to an increase in protein $(30,50,80$, and $100 \mu \mathrm{g}$ of protein). The rat heart was used as positive control $(\mathrm{Ct}+)$ for ACE2 activity and protein expression. ACE = angiotensin-converting enzyme. ${ }^{\dagger} \mathrm{P}<0.05$ compared to soleus and plantaris muscles; $\ddagger \mathrm{P}<0.01$ compared to soleus muscle (Student $t$-test). 
ciated with increased ACE1 activity and a greater fraction of type II fibers, so that this type of polymorphism may be related to power performance sports $(3,10)$.

The discovery of ACE2 in 2000 (11) and our identification of this enzyme in skeletal muscle broaden the concept of tissue RAS $(1,2)$. In hypertension, lower ACE2 mRNA and protein levels culminate in elevated Ang II levels. This effect could reduce myocardial blood flow preferentially via coronary vasoconstriction or microcirculatory dysfunction. ACE2 is enhanced by ACE1 inhibitors or angiotensin receptor blockers $(12,18)$.

Crackower et al. (13) showed that deletion of ACE2 in mice results in elevated cardiac and plasma Ang II together with impaired cardiac contractility and left ventricle dilation. Studies have proposed that ACE2 might protect against CVD by diminishing Ang II concentration, consequently resulting in augmented Ang-(1-7) generation (19). This implies that there is a balance between ACE1 and ACE2 in the control of the Ang II and Ang-(1-7) levels.

Cardiac overexpression of ACE2 exerts a protective influence on the heart during myocardial infarction by preserving cardiac function, left ventricle wall motion and contractility,

\section{References}

1. Griendling KK, Murphy TJ, Alexander RW. Molecular biology of the renin-angiotensin system. Circulation 1993; 87: 18161828.

2. Phillips MI, de Oliveira EM. Brain renin angiotensin in disease. J Mol Med 2008; 86: 715-722.

3. Jones A, Woods DR. Skeletal muscle RAS and exercise performance. Int J Biochem Cell Biol 2003; 35: 855-866.

4. Reneland $\mathrm{R}$, Lithell $\mathrm{H}$. Angiotensin-converting enzyme in human skeletal muscle. A simple in vitro assay of activity in needle biopsy specimens. Scand J Clin Lab Invest 1994; 54 : 105-111.

5. Ward PE, Russell JS, Vaghy PL. Angiotensin and bradykinin metabolism by peptidases identified in skeletal muscle. Peptides 1995; 16: 1073-1078.

6. Agoudemos MM, Greene AS. Localization of the reninangiotensin system components to the skeletal muscle microcirculation. Microcirculation 2005; 12: 627-636.

7. Zoll J, Monassier L, Garnier A, N'Guessan B, Mettauer B, Veksler V, et al. ACE inhibition prevents myocardial infarction-induced skeletal muscle mitochondrial dysfunction. $J$ Appl Physiol 2006; 101: 385-391.

8. Fabre JE, Rivard A, Magner M, Silver M, Isner JM. Tissue inhibition of angiotensin-converting enzyme activity stimulates angiogenesis in vivo. Circulation 1999; 99: 3043-3049.

9. Hruskovicova H, Dzurenkova D, Selingerova M, Bohus B, Timkanicova B, Kovacs $L$. The angiotensin converting enzyme I/D polymorphism in long distance runners. J Sports Med Phys Fitness 2006; 46: 509-513.

10. Williams AG, Day SH, Folland JP, Gohlke P, Dhamrait S, Montgomery HE. Circulating angiotensin converting enzyme activity is correlated with muscle strength. Med Sci Sports Exerc 2005; 37: 944-948. and by attenuating left ventricle wall thinning (20).

The significance of the present study is that, by characterization of ACE2 in skeletal muscle, future therapies targeting ACE2 might be developed for the treatment of peripheral abnormalities in skeletal muscle mediated by hypertension and other CVD such as vasomotor tonus imbalance induced by high peripheral vasoconstriction, increased wall-to-lumen vascular ratio, and microvascular rarefaction. Moreover, the present results might have implications in sports performance.

This study brings new insight into the role of ACE1 in skeletal muscle and presents the first report on ACE2 activity and protein expression in skeletal muscle. As ACE2 differs in its specificity and physiological role from ACE1, these results might be relevant for the treatment of skeletal muscle pathologies in CVD.

\section{Acknowledgments}

Research supported by a CNPq-PIBIC fellowship (\#155501/2004-05). T. Fernandes was the recipient of a Master's fellowship from FAPESP (\#07/56771-4).
11. Tipnis SR, Hooper NM, Hyde R, Karran E, Christie G, Turner AJ. A human homolog of angiotensin-converting enzyme. Cloning and functional expression as a captopril-insensitive carboxypeptidase. J Biol Chem 2000; 275: 33238-33243.

12. Ferrario CM. Angiotensin-converting enzyme 2 and angiotensin-(1-7): an evolving story in cardiovascular regulation. Hypertension 2006; 47: 515-521.

13. Crackower MA, Sarao R, Oudit GY, Yagil C, Kozieradzki I, Scanga SE, et al. Angiotensin-converting enzyme 2 is an essential regulator of heart function. Nature 2002; 417: 822828.

14. Alves MF, Araujo MC, Juliano MA, Oliveira EM, Krieger JE, Casarini DE, et al. A continuous fluorescent assay for the determination of plasma and tissue angiotensin l-converting enzyme activity. Braz J Med Biol Res 2005; 38: 861-868.

15. Sanders PM, Russell ST, Tisdale MJ. Angiotensin II directly induces muscle protein catabolism through the ubiquitinproteasome proteolytic pathway and may play a role in cancer cachexia. Br J Cancer 2005; 93: 425-434.

16. Gordon SE, Davis BS, Carlson CJ, Booth FW. ANG II is required for optimal overload-induced skeletal muscle hypertrophy. Am J Physiol Endocrinol Metab 2001; 280: E150-E159.

17. McBride TA. AT1 receptors are necessary for eccentric training-induced hypertrophy and strength gains in rat skeletal muscle. Exp Physiol 2006; 91: 413-421.

18. Ferrario CM, Jessup J, Chappell MC, Averill DB, Brosnihan $\mathrm{KB}$, Tallant EA, et al. Effect of angiotensin-converting enzyme inhibition and angiotensin II receptor blockers on cardiac angiotensin-converting enzyme 2. Circulation 2005; 111: 2605-2610.

19. Grobe JL, Mecca AP, Lingis M, Shenoy V, Bolton TA, Macha- 
do JM, et al. Prevention of angiotensin II-induced cardiac remodeling by angiotensin-(1-7). Am J Physiol Heart Circ Physiol 2007; 292: H736-H742.

20. Der Sarkissian S, Grobe JL, Yuan L, Narielwala DR,
Walter GA, Katovich MJ, et al. Cardiac overexpression of angiotensin converting enzyme 2 protects the heart from ischemia-induced pathophysiology. Hypertension 2008; 51 : 712-718. 